\section{(2) OPEN ACCESS}

\title{
Anatomy and function of the fornix in the context of its potential as a therapeutic target
}

\author{
Suhan Senova, ${ }^{1}$ Anton Fomenko (1) ${ }^{2,3}$ Elise Gondard, ${ }^{3}$ Andres M Lozano (i) 2,3
}

\begin{abstract}
- Additional material is published online only. To view please visit the journal online (http://dx.doi.org/10.1136/ jnnp-2019-322375).

${ }^{1}$ Neurosurgery, Institut Mondor de recherche biomedicale, Créteil, Île-de-France, France ${ }^{2}$ Division of Neurosurgery, University of Toronto, Toronto, Ontario, Canada

${ }^{3}$ University Health Network, Toronto, Ontario, Canada
\end{abstract}

Correspondence to Dr Andres M Lozano,

Neurosurgery, Toronto Western Hospital, University of Toronto, Toronto, ON M5T2S8, Canada; lozano@uhnresearch.ca

SS and AF contributed equally.

SS and AF are joint first authors.

Received 4 November 2019 Revised 10 February 2020

Accepted 15 February 2020 Published Online First 4 March 2020

Check for updates

(C) Author(s) (or their employer(s)) 2020. Re-use permitted under CC BY-NC. No commercial re-use. See rights and permissions. Published by BMJ.

To cite: Senova S, Fomenko A, Gondard E, et al. J Neurol Neurosurg Psychiatry

2020;91:547-559.

\section{ABSTRACT}

The fornix is a white matter bundle located in the mesial aspect of the cerebral hemispheres, which connects various nodes of a limbic circuitry and is believed to play a key role in cognition and episodic memory recall. As the most prevalent cause of dementia, Alzheimer's disease (AD) dramatically impairs the quality of life of patients and imposes a significant societal burden on the healthcare system. As an established treatment for movement disorders, deep brain stimulation (DBS) is currently being investigated in preclinical and clinical studies for treatment of memory impairment in $A D$ by modulating fornix activity. Optimal target and stimulation parameters to potentially rescue memory deficits have yet to be determined. The aim of this review is to consolidate the structural and functional aspects of the fornix in the context of neuromodulation for memory deficits. We first present an anatomical and functional overview of the fibres and structures interconnected by the fornix. Recent evidence from preclinical models suggests that the fornix is subdivided into two distinct functional axes: a septohippocampal pathway and a subiculothalamic pathway. Each pathway's target and origin structures are presented, followed by a discussion of their oscillatory dynamics and functional connectivity. Overall, neuromodulation of each pathway of the fornix is discussed in the context of evidence-based forniceal DBS strategies. It is not yet known whether driving fornix activity can enhance cognition-optimal target and stimulation parameters to rescue memory deficits have yet to be determined.

\section{INTRODUCTION}

The fornix is a white matter bundle located in the mesial aspect of the cerebral hemispheres, which connects various nodes of a limbic circuitry and is believed to play a key role in cognition and episodic memory recall. ${ }^{12}$ While fornix lesions impair memory, it is not yet known whether driving fornix activity can enhance cognition. Stimulating a distributed fibre bundle such as the fornix could be a powerful and efficient method of targeting interconnected brain regions involved in cognitive processes. ${ }^{2}{ }^{3}$ Importantly, brain-wide targets could be simultaneously modulated by stimulation of forniceal fibres projecting from and to widely distributed regions. A detailed knowledge of the neuronal structures interconnected by the fornix bundle would be crucial to delineate the antidromic and orthodromic effects of neuromodulation. A comprehensive knowledge of the forniceal anatomy could also serve to inform clinicians to cognitive subpathways and corresponding memory deficits that arise from neurodegenerative disease or lesions. Likewise, careful consideration of structures targeted by forniceal projections could also inform the electrophysiologist of optimal deep brain stimulation (DBS) parameters to try to rescue particular types of memory deficits encountered in Alzheimer's disease (AD), traumatic brain injuries, epilepsy or strokes.

Neuromodulation of the fornix by electrical DBS has recently been investigated as a treatment for memory impairment in patients with $\mathrm{AD} .{ }^{4}$ In a phase I study, one-third of patients showed improvement or slowing in the rate of cognitive decline. In a recent phase II study, it was suggested that the subgroup of patients with $\mathrm{AD}$ over the age of 65 tended to experience a slower deterioration in memory, and a phase III trial is currently ongoing to study the neuropsychological effects of fornix DBS in this patient subgroup. ${ }^{5}$ Despite multiple clinical trials underway, optimal target and stimulation parameters to rescue memory deficits have yet to be determined, and the therapeutic benefit is modest. ${ }^{25}$

Here, we review structural and functional aspects of the fornix in the context of neuromodulation for memory deficits. We suggest that the fornix should be subdivided into two distinct anatomo-functional axes: a forniceal septohippocampal (SHP) pathway and a forniceal subiculothalamic pathway. Each pathway's target and origin structures will first be presented, followed by a discussion of their oscillatory dynamics and functional connectivity. In the context of evidence-based therapeutic forniceal DBS strategies, neuromodulation of each axis will be discussed with supporting preclinical and clinical evidence.

\section{Gross anatomy of the fornix}

The fornix is a thin arched white matter bundle composed of myelinated association, projection and commissural fibres located in the mesial aspect of the cerebral hemispheres (figure 1). The human fornix contains approximately $1.2-2.7$ million fibres in each hemisphere ${ }^{67}$ and fills a total volume of about 1000-1800 cubic millimetres. ${ }^{8}{ }^{9}$ As a major hippocampal output structure, the fornix stretches longitudinally from the mesial temporal lobe to the diencephalon and basal forebrain. Medial to the floor of the temporal horn of the lateral ventricle, hippocampal fibres collect into a thin lamina known as the alveus. Fibres from the subiculum join the alveus as it courses posteromedially and bundles into the fimbria of the fornix. 


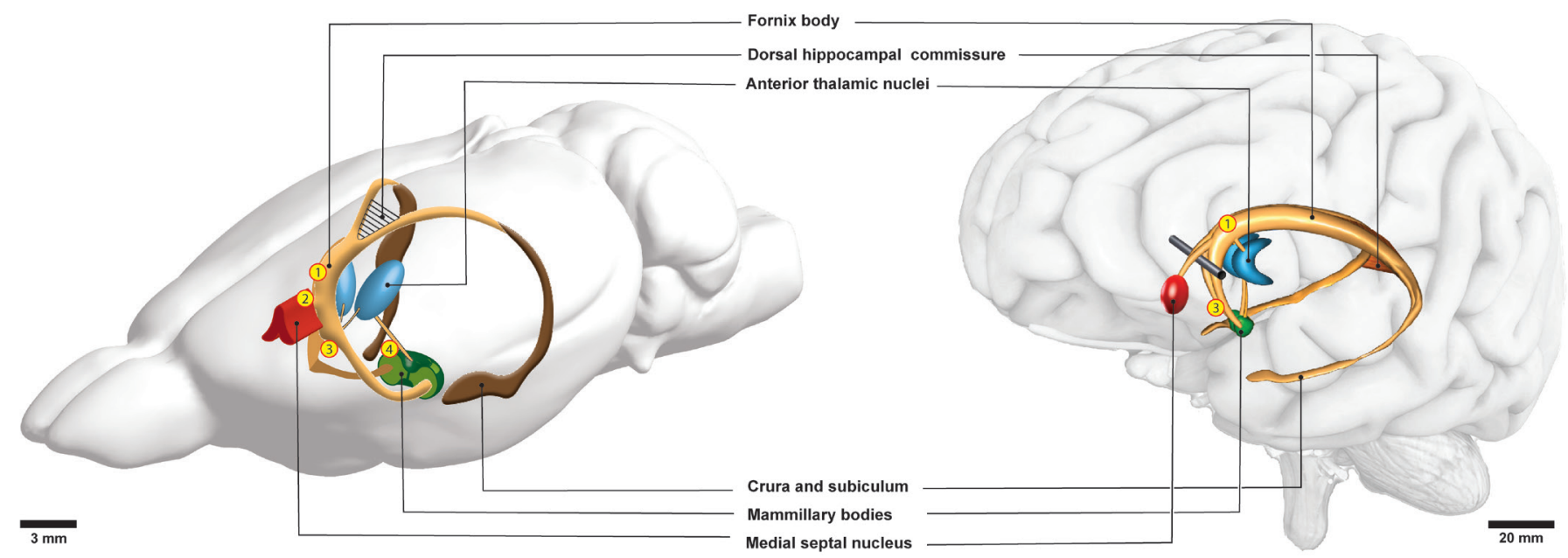

Figure 1 Gross anatomy of the rodent (left) and human (right) fornix. Locations where deep brain stimulation has been performed in rodents and humans are indicated by numerals - 1: stimulation of the post-commissural dorsal fornix; 2: stimulation of the pre-commissural fornix, 3: stimulation of the postcommissural ventral fornix; 4: stimulation of the mammillothalamic tract. The results associated with these sites of stimulation are detailed in tables $2-5$.

As the fimbria enlarge in cross-sectional area by collecting additional fibres, they become known as the crura of the fornix. The crura arch supero-anteriorly under the splenium of the corpus callosum and project contralaterally via the thin triangular forniceal commissure, also known as the psalterum or dorsal hippocampal commissure. The crura run paracentrally to form the

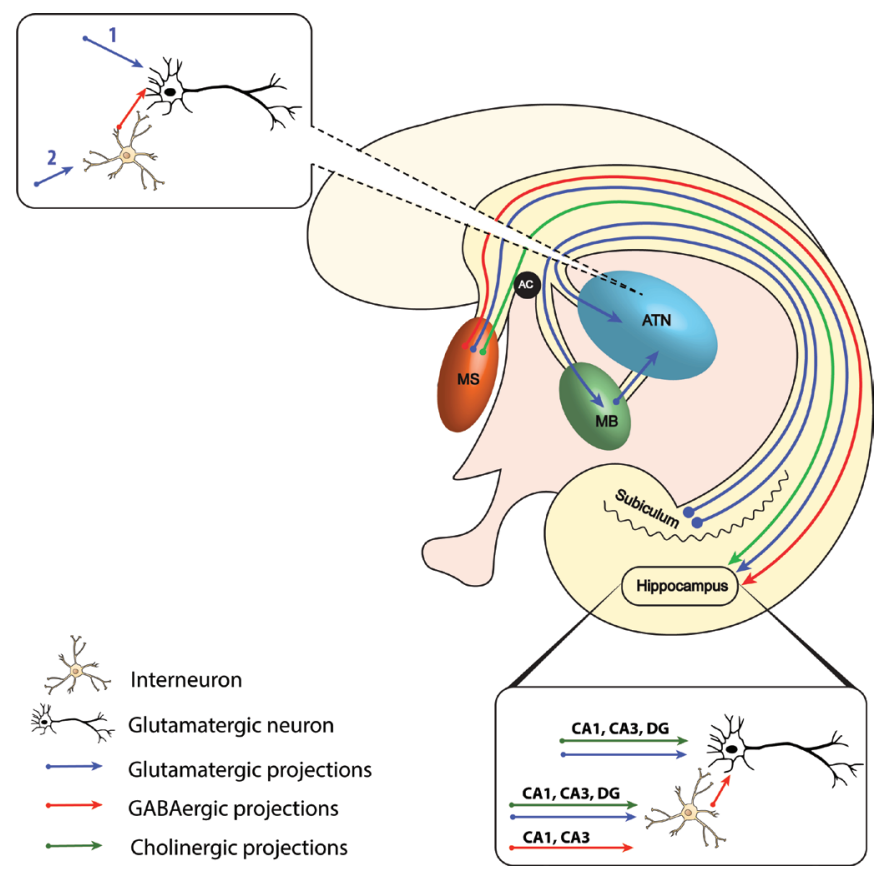

Figure 2 Simplified neurochemical anatomy of the fornix highlighting the presence of a septohippocampal pathway and a subiculothalamic pathway. The fornix is composed of neural populations comprising GABAergic, glutamatergic and cholinergic fibres. Septohippocampal projections encompass slow-firing $(0.5-5 \mathrm{~Hz})$ cholinergic, fast-firing and burst-firing $(10-18 \mathrm{~Hz})$ GABAergic and glutamatergic neurons. The subiculothalamic pathway comprises chiefly glutamatergic neurons projecting to the mammillary bodies and the anterior thalamic nuclei. $A C$, anterior commissure; DG, dentate gyrus; ATN, anterior thalamic nuclei; MB, mammillary bodies; MS, medial septum. forniceal body, which arches over the thalamus and under the septum pellucidum. Rostrally, the fornix body bifurcates into left and right columns that descend into the basal forebrain anterior to the interventricular foramina. The fornix columns divide at the anterior commissure-fibres travelling anteriorly form the pre-commissural fornix, while those curving posteriorly make up the post-commissural fornix. This division in structure reflects the two major forniceal functional pathways. Pre-commissural fibres house the septohippocampal pathway, also projecting to the forebrain. Post-commissural tracts originate from the subiculum and project to the thalamus, forming the direct subiculothalamic pathway, and the indirect subiculothalamic pathway which relays via the mammillary bodies (figure 2). Important cross-species differences exist between primate and rodent fornices, in part due to the distinct spatial configuration of their respective hippocampi. The rodent hippocampus is transposed more rostrodorsally, with its dorsal and ventral components hinged by a 90 -degree flexure ${ }^{10}$ and envelops the hippocampal formation as a sheet of fimbria and alveus fibres. ${ }^{11}$ Compared with primates, rodents have a more developed commissural system-their dorsal commissure spans almost the entire longitudinal axis of the fornix. In addition, a thin transverse lamina known as the ventral hippocampal commissure (VHC) is found in non-human primates and rodents just ventral to the columns at the level of the subfornical organ. ${ }^{12} 13$ The VHC carries decussating dentate gyrus fibres ${ }^{14}$ and is probably absent in humans, though histopathological evidence exists of decussating fibres in this region ${ }^{15} 16$ which later studies were unable to reproduce. ${ }^{17}$ The dorsal fornix is the murine homologue to the human fornix body and its fibres arise from the temporal hippocampal pole and course along the undersurface of the corpus callosum, medial to the septal hippocampus. ${ }^{18}$ The thin dorsal fornix eventually disappears at the anterior commissure, where fibres of the rodent fimbria-fornix divide to reach their terminal nuclei. ${ }^{19}$

\section{FORNICEAL PATHWAYS AND MEMORY IMPAIRMENT Lesions of the fornix}

In early literature, surgical lesioning of the anterior fornix for treatment of epilepsy was only rarely associated with subsequent memory deficits. ${ }^{20}$ More recently, cognitive deficits in episodic 
Table 1 Studies examining the effects of fornix lesions in rodents, non-human primates and humans, along with associated behavioural deficits

\begin{tabular}{|c|c|c|c|}
\hline Study & Species & Forniceal lesion location & Behavioural deficits \\
\hline Nilsson et al 1987 & Rat & Post-commissural dorsal fornix & Spatial memory impairment \\
\hline Aggleton et $a l^{23}$ & Rat & Post-commissural dorsal fornix & Spatial memory impairment but no recognition memory impairment \\
\hline Waburton and Aggleton 1999 & Rat & Post-commissural dorsal fornix & Spatial memory impairment but no recognition memory impairment \\
\hline Howard et al 1989 & Rat & Post-commissural dorsal fornix & Spatial memory impairment \\
\hline Jeltsch et al 1994 & Rat & Post-commissural dorsal fornix & Spatial memory impairment \\
\hline Fletcher et al 2006 & Rat & Post-commissural dorsal fornix & Spatial memory impairment \\
\hline Mala et al 2013 & Rat & Post-commissural dorsal fornix & Spatial memory impairment \\
\hline Ennaceur et al 1997 & Rat & Post-commissural dorsal fornix & Spatial memory impairment but no recognition memory impairment \\
\hline Waburton et al 2000 & Rat & Post-commissural dorsal fornix & Spatial memory impairment but no recognition memory impairment \\
\hline Phillips and LeDoux 1995 & Rat & Post-commissural dorsal fornix & Contextual fear conditioning impairment \\
\hline Maren and Fanselow 1997 & Rat & Post-commissural dorsal fornix & Contextual fear conditioning impairment \\
\hline Antoniadis and McDonald 2006 & Rat & Post-commissural dorsal fornix & Contextual fear conditioning impairment \\
\hline Laurent-Demir and Jaffard 2000 & Rat & Post-commissural dorsal fornix & No impairment in acoustic fear conditioning \\
\hline Baldi et al 2013 & Rat & Post-commissural dorsal fornix & No impairment in acoustic fear conditioning \\
\hline Baldi et al 1998 & Rat & Post-commissural dorsal fornix & Deficit in encoding but not retrieval in passive avoidance learning \\
\hline Sziklas and Petrides 2002 & Rat & Pre-commissural fornix & Spatial memory impairment but no impairment with a visual cue \\
\hline Saunders et al 2005 & Monkey & Fornix body & Impaired visual recognition \\
\hline Wilson et al 2007 & Monkey & Fornix body & Impairment in object discrimination \\
\hline Buckley et al 2008 & Monkey & Fornix body & Impairment of encoding but no recall of visuospatial memory \\
\hline Kwok and Buckley 2010 & Monkey & Fornix body & Impaired encoding of rapidly learnt visuospatial discrimination \\
\hline Adamovich et al 2009 & Human & Bilateral anterior columns of fornix & Retrograde and anterograde amnesia \\
\hline Baweja et al 2015 & Human & Bilateral anterior columns of fornix & Retrograde and anterograde amnesia \\
\hline Cameron et al 1981 & Human & Left anterior column of fornix & Verbal memory deficit \\
\hline Korematsu et al 2010 & Human & Left anterior column of fornix & Retrograde and anterograde amnesia \\
\hline Vann et al 2008 & Human & Anterior column of fornix & Anterograde amnesia but spared recognition memory \\
\hline Gupta et al 2015 & Human & Left anterior column and fornix body & Retrograde and anterograde amnesia \\
\hline Hodges et al 1991 & Human & Anterior genu of fornix & Anterograde amnesia \\
\hline McMakin et al 1996 & Human & Anterior genu of fornix & Anterograde amnesia \\
\hline Murr et al 2012 & Human & Anterior genu of fornix & Anterograde amnesia \\
\hline Rizek et al 2013 & Human & Anterior genu of fornix & Anterograde amnesia \\
\hline Kauppila et al 2018 & Human & Anterior genu of fornix & Anterograde verbal memory \\
\hline Chen et al 2008 & Human & Fornix body & Anterograde amnesia \\
\hline Carota et al 2013 & Human & Crura and body of the fornix & Anterograde amnesia \\
\hline Tucker et al 1988 & Human & Left fornix body & Anterograde amnesia \\
\hline Yeo et al 2013 & Human & Crura of the fornix & Anterograde amnesia \\
\hline
\end{tabular}

memory are increasingly being reported in patients with injuries to the fornix (table 1). ${ }^{21-23}$ Bilateral lesions of the fornix anterior columns are associated with anterograde and retrograde amnesia. $^{24} 25$ The fornix carries distinct functions depending on laterality; the left fornix primarily carries verbal memory information, while the right carries visuospatial memory information. ${ }^{26-28}$ In addition, the medial fornix carries fibres from the caudal hippocampus, which integrates object recognition within a spatial context such as in scene learning. The lateral aspect of the fornix is thought to carry projections from the more rostral hippocampus, which processes interoceptive signals for emotional and motivational learning and memory. ${ }^{29} 30$ After forniceal lesions, a relative sparing of recognition is seen when compared with the loss of the recall of episodic information. ${ }^{23} 27$ Moreover, as nodes of the fornix, the mammillary bodies are classically considered to provide a relay for indirect hippocampal inputs to the anterior thalamic nuclei. In such models, the mammillary bodies do not have an independent role in memory. However, the medial aspect of the mammillary bodies' contribution to memory is more dependent on afferents from the ventral tegmental nucleus of Gudden than from the hippocampal formation, while the lateral mammillary bodies, connected with the dorsal tegmental nucleus of Gudden, participate in generating head-direction signals. ${ }^{31}$

\section{Early Alzheimer's pathology and the fornix}

The neuropathological hallmarks of $\mathrm{AD}$, such as extracellular beta-amyloid and intracellular tau, can provide insight into the neuroanatomical progression of the disease and shed light into potential neuroanatomical hotspots for neuromodulation-based therapy. ${ }^{32} 33$ The appearance of hyperphosphorylated cytoskeletal tau within the brain is found even before cognitive deficits are clinically apparent (ie, Braak and Braak AD stages 0 and 1), classically manifesting first in the entorhinal and transentorhinal regions. ${ }^{34}$ However, recent pathoanatomical studies in brains from cognitively intact individuals have found evidence of immunoreactive neuronal tau cytoskeletal pathology in subcortical nuclei interconnected by the fornix. ${ }^{34} 35$ Areas with presence of tau deposits in Braak stages 0 or 1 included the perifornical and lateral region of the hypothalamus, the dorsomedial, ventromedial, tuberomammillary and supramammillary nuclei, and subnuclei of the amygdala and thalamus known to be synaptically connected to the hippocampus via the forniceal 
and entorhinal pathways. ${ }^{34}$ Since PET imaging studies point to the distribution of tau signal as a strong predictor of future local neurodegeneration and atrophy, neuromodulation of the fornix or its subnuclei may represent a logical strategy. ${ }^{33}$ Indeed, studies in animal and in vitro models of $\mathrm{AD}$ have shown that synaptic activation via chronic DBS reduced pathological tau and provided synaptic neuroprotection. ${ }^{36} 37$

In addition to patterns of tau accumulation, another biomarker of $\mathrm{AD}$ correlating with disease severity includes alterations in cortical EEG dynamics. ${ }^{38}$ As a cortical dementia, hallmarks of underlying neuropathological changes in $\mathrm{AD}$ include decreases in lower cortical frequency bands (alpha and beta), and an increase in theta and delta rhythms. ${ }^{38} 39$ Reduced coherence of cortical alpha and beta bands is also seen in $\mathrm{AD}$, suggesting losses in cortical synaptic function. ${ }^{38-40}$ Since the fornix is a deep structure connecting chiefly subcortical nuclei, at the time of this writing no DBS studies have studied cortical EEG changes in response to DBS, though it merits future study as a potentially useful outcome measure to monitor response to neuromodulation treatment.

\section{Forniceal connectivity and memory impairment}

Functional MRI studies are beginning to suggest that degeneration of the fornix bundle itself may precede hippocampal dysfunction and predict cognitive impairment better than structural measures such as hippocampal atrophy. ${ }^{41}$ Connectivity data from diffusion tensor imaging studies suggest that forniceal measures correlate with episodic memory performance in various neuropathological conditions, as well as during brain development and ageing. On imaging, macrostructural and microstructural alterations of the fornix have been found to be robust predictors of episodic memory performance, independent of age and associated structural pathology. ${ }^{142}$ Specifically, in $\mathrm{AD}$, atrophy of the fornix on structural MRI and reductions in fractional anisotropy have often been reported. ${ }^{43-45}$ Fornix atrophy may predict the onset of $\mathrm{AD},{ }^{41}$ even prior to clinical manifestations. Moreover, fornix fractional anisotropy reduction is correlated with cognitive decline in $\mathrm{AD} .{ }^{46}$ While fornix lesions or degeneration are associated with memory impairment, it is not yet known whether driving fornix activity can enhance these functions.

\section{SEPTOHIPPOCAMPAL PATHWAY}

\section{Anatomy and spontaneous activity}

The projections from the medial septum (MS) to the hippocampus form the septohippocampal forniceal pathway and are proposed to have important roles in cognition by modulating the activity of episodic memory circuits. ${ }^{47-49}$ As the terminal structure of this forniceal pathway, the hippocampus is necessary for episodic memory, and is involved in the storage and recall of autobiographical events. ${ }^{50} 51$ Sensory cue inputs from the entorhinal cortical grid cells and memory-related internal brain activities govern the firing of hippocampal neurons. ${ }^{52-55}$ Traditionally, the hippocampus has been thought to exhibit two dominant and behaviour-dependent local field potential (LFP) patterns: theta rhythm and large-amplitude irregular activity with sharp waves. ${ }^{56}$ Theta rhythm is a large-amplitude $(1-2 \mathrm{mV})$ $4-10 \mathrm{~Hz}$ sinusoidal oscillation in the rat, ${ }^{5758}$ with two defined subtypes: type $1(7-10 \mathrm{~Hz})$ is associated with voluntary movement and exploratory behaviour, whereas type $2(4-6 \mathrm{~Hz})$ is present during immobility, rapid eye movement (REM) sleep or urethane anaesthesia. ${ }^{59}$
Theta oscillations are understood to be critical in hippocampal mnemonic and learning functions. ${ }^{58}$ 60-66 The MS projections through the fornix are involved in hippocampal theta modulation. ${ }^{47,62,67,68}$ Rhythmically discharging cells of the MS in the diagonal band vertical nucleus fire synchronously with theta and may be involved in its pacing. ${ }^{58,67,69-76}$ In freely moving rats, MS neuron activity can be negatively (during sharp wave ripples) or positively (during theta waves) correlated with the activity of hippocampal neurons. ${ }^{75}$ The MS decreases the spiking of hippocampal pyramidal neurons and reduces their ability to fire in trains. $^{49,77}$ Septohippocampal oscillatory regulation of neuronal activity also precisely synchronises postsynaptic potentials arriving at hippocampal pyramidal cells. ${ }^{78}$

Conversely, disrupting or lesioning the MS eliminates the hippocampal theta rhythm. During MS inactivation by muscimol ${ }^{79}$ or lidocaine ${ }^{77}$ grid cells recorded in the medial entorhinal cortex lose their spatial periodicity. Also, loss of theta via MS lesioning significantly alters performance on spatial ${ }^{49,80,81}$ as well as non-spatial tasks. ${ }^{80,82}$ However, after extinguishing hippocampal theta rhythm via pharmacological inactivation of the MS, ${ }^{77,80}$ location-specific firing of hippocampal place cells are maintained. Sensory cues seemingly guide hippocampal neural firing in rats, whereas MS inputs prevail over shorter timescales, ${ }^{83}$ and both support the formation of hippocampal spatial firing fields.

In rats, reciprocal hippocamposeptal projections exist to the cholinergic nuclei of the MS via forniceal GABAergic neurons. ${ }^{84,85}$ The CA1 to MS fibres are sparse and project unilaterally, whereas those originating from CA2-3 project extensively and bilaterally. ${ }^{86}$ Topographically, the dorsal CA3 innervates the dorsal and medial parts of the MS; conversely, axons of the ventral CA3 reaches the lateral and ventral parts of the MS ${ }^{86}$ The hippocamposeptal tract has been implicated in inhibiting ${ }^{87,88}$ and modulating ${ }^{88}$ theta generators in the septal region. ${ }^{85}$ For instance, in vitro rodent hippocampal preparations demonstrated the role of hippocamposeptal modulation in phasing the spiking of MS GABAergic neurons, while inhibiting acetylcholinergic and glutamatergic neurons in the same region. ${ }^{89}$

\section{Electrical stimulation of the septohippocampal pathway}

Diverse stimulation parameters of the SHP have been explored. High-frequency $(100 \mathrm{~Hz})$ chronic or acute stimulation of the rodent SHP were found to induce hippocampal long-term potentiation and neurogenesis. ${ }^{90}$ Furthermore, upregulation of genes involved in synaptic function, cell survival and neurogenesis was observed in molecular expression studies after such SHP stimulations. $^{91}$

Because theta oscillations are critically involved in memory, SHP stimulation at theta frequencies has been thoroughly investigated in rodents (figure 1; table 2). Specifically, electrical stimulation of the MS in the $3-12 \mathrm{~Hz}$ range serves to experimentally mirror physiologic theta-like hippocampal LFP frequencies. ${ }^{92-95}$ Indeed, $5-7 \mathrm{~Hz}$ DBS exhibits electrophysiological characteristics similar to those of spontaneously occurring theta field activity, ${ }^{96}$ while higher stimulation frequencies produce hippocampal desynchronisation. ${ }^{97-100}$ Although CA1 pyramidal cells respond maximally to $6-8 \mathrm{~Hz}$ MS stimulation, electrical stimulation of medial septal nuclei does not produce typical physiological hippocampal theta-related activity. ${ }^{101}$ Nevertheless, restoring theta-like hippocampal activity by stimulation of the SHP was shown to rescue memory deficits in rats after MS inactivation. ${ }^{95}$ More precisely, irregular SHP stimulation resulted in little rhythmicity, while a fixed stimulatory frequency of $7.7 \mathrm{~Hz}$ triggered by 
Table 2 Stimulation of the post-commissural dorsal fornix in rodents and patients with epilepsy, along with main findings

\begin{tabular}{|c|c|c|c|}
\hline Study & Model & Stimulation pattern & Main findings \\
\hline William and Givens 2003 & Rats & Acute single pulses & Hippocampal theta reset \\
\hline \multirow[t]{3}{*}{ McNaughton et al 2006} & \multirow[t]{3}{*}{$\begin{array}{l}\text { Rats, medial septum pharmacologically } \\
\text { inactivated }\end{array}$} & Acute fixed theta & $\begin{array}{l}\text { Increases theta power, improves initial performance in Morris Water } \\
\text { Maze (MWM) }\end{array}$ \\
\hline & & Acute irregular theta & Does not increase theta power, nor improves performance in MWM \\
\hline & & Acute closed loop theta & $\begin{array}{l}\text { Increases theta power, improves performance in MWM a sustained } \\
\text { way }\end{array}$ \\
\hline \multirow[t]{3}{*}{ Shirvalkar et al 2010} & \multirow[t]{3}{*}{$\begin{array}{l}\text { Rats, medial septum pharmacologically } \\
\text { inactivated }\end{array}$} & Acute theta & $\begin{array}{l}\text { Does not improve theta-gamma coupling in hippocampus nor memory } \\
\text { performance }\end{array}$ \\
\hline & & Acute $100 \mathrm{~Hz}$ & $\begin{array}{l}\text { Does not improve theta-gamma coupling in hippocampus nor memory } \\
\text { performance }\end{array}$ \\
\hline & & Acute TBS & $\begin{array}{l}\text { Restores theta-gamma coupling in hippocampus and memory } \\
\text { performance in radial water maze }\end{array}$ \\
\hline Hao et al 2015 & Mouse model of Rett syndrome & Chronic $100 \mathrm{~Hz}$ & $\begin{array}{l}\text { Improves LTP and neurogenesis in hippocampus, and contextual fear } \\
\text { memory }\end{array}$ \\
\hline Miller et al 2015 & Patients with epilepsy & Acute TBS & Improvement in visuospatial memory \\
\hline
\end{tabular}

LTP, long-term potentiation; MWM, Morris water maze; TBS, theta burst stimulation.

supramammillary nucleus theta rhythmicity restored theta-like rhythmicity with abnormal waveforms. While both stimulation paradigms improved memory deficits, the latter was the most efficient. Thus, despite incomplete physiological reinstatement, promotion of synchronous low-frequency phasic firing rescues learning processes in rodent models. DBS of the SHP has also been shown to restore cognitive deficits associated with pathological brain states. For instance, in a rat model of traumatic brain injury, theta stimulation of the MS restored hippocampal theta oscillations and yielded improvements in object exploration when performed chronically, ${ }^{102}$ as well as improved spatial working memory when administered acutely before training. ${ }^{103}$

Moreover, temporal co-ordination of theta and gamma rhythms is important for sequential memory retrieval, ${ }^{104,105}$ sequential representations during learning, ${ }^{106,107}$ and facilitation of synaptic plasticity. ${ }^{108,109}$ After pharmacological inactivation of the MS, Shirvalkar and colleagues reported that acute theta burst stimulation (TBS) of the SHP within the fimbria-fornix region increased hippocampal theta-gamma coupling (TGC) in amnestic animals and rescued memory performance in the Morris Water Maze. ${ }^{110}$ Notably, single-trial spatial memory performance in rats was predicted by the power comodulation of theta $(4-10 \mathrm{~Hz})$ and low gamma $(30-50 \mathrm{~Hz})$ rhythms in the hippocampus during the retrieval phase. However, TGC was weak when memory failed and was unavailable during spatial exploration. Thus, TGC may be necessary for memory encoding and retrieval.

TBS is a distinct pattern of stimulation that has been investigated for its physiological relevance. Non-selective septal TBS resets hippocampal theta cell bursting during active behaviour while increasing theta synchronisation. ${ }^{96,111-115}$ This reset persists for 600-900 ms and enables dentate granule cell depolarisation at the time of sensory input arrival from the entorhinal cortex. This synchrony facilitates long-term potentiation, enabling synaptic plasticity, ${ }^{116,117}$ and ultimately enhancing the encoding of incoming information. ${ }^{118-121}$ TBS also entrains the spiking of hippocampal place cells, ${ }^{115}$ potentiates population spikes at CA $1^{122}$ and temporally regulates the place field spatial properties during active exploration. ${ }^{115}$

\section{MS neuronal subpopulations}

Septohippocampal projections encompass immunohistochemically and electrophysiologically distinct slow-firing
$(0.5-5 \mathrm{~Hz})$ cholinergic, fast-firing and burst-firing $(10-18 \mathrm{~Hz})$ GABAergic and glutamatergic neurons with heterogeneous firing patterns $^{123-138}$ (figure 2). Co-synthesis of glutamate in cholinergic and GABAergic neurons has also been reported. ${ }^{131,133}$ Connections include sparse GABAergic inputs from lateral to medial septal cholinergic neurons, reciprocal connections between medial septal cholinergic and GABAergic neurons, and also glutamatergic neurons within the MS synapsing onto neighbouring cholinergic and GABAergic neurons. ${ }^{15,139-141}$ In primates, the MS projects to the hippocampus in a topographically oriented fashion: medial portions project via medial fornix fibres, and the lateral MSN project via the lateral fornix. ${ }^{29,142}$ To understand the physiology of the rodent SHP, the projection patterns for each MS neuronal subtype will be reviewed.

\section{MS GABAergic neurons}

\section{Connectivity}

Medial septal GABAergic fibres terminate on vasoactive intestinal polypeptide-immunoreactive interneurons in strata pyramidale and lacunosum-moleculare of the $\mathrm{CA} 1^{143}$ and on calretinin-immunoreactive and neuropeptide Y-immunoreactive GABAergic interneurons in the stratum radiatum of the CA1 and stratum lucidum of CA3. ${ }^{127,144-146}$ Inhibitory inputs terminate on neurons containing cholecystokinin, somatostatin and parvalbumin in the stratum oriens. ${ }^{127,144,146,147}$

\section{Electrophysiology}

GABAergic septohippocampal projection cells are crucial for hippocampal theta generation. ${ }^{59,67,74,75,148-151}$ For instance, the frequency of theta in urethane-anaesthetised rats depends on the activity of medial septal GABAergic cells. ${ }^{152}$ GABAergic neurons may pace the hippocampus in vivo via tonic, cluster or burst-firing patterns of discharge mediated by low-threshold spikes and prominent hyperpolarisation-activated cation (Ih) currents. ${ }^{135,136,153}$ Rhythmic bursting activity, observed at theta frequencies during wakefulness and REM sleep, is more pronounced in GABAergic neurons that contain parvalbumin. These neurons display higher discharge rate and longer burst duration, ${ }^{136,154-156}$ which may result from the calcium-buffering properties of parvalbumin. ${ }^{138}$ Local GABAergic MS neurons typically do not contain parvalbumin. ${ }^{157}$ Burst-firing neurons tonically fire during slow-wave sleep, and their discharge rates remain high across the sleep/ 
wake cycle. Rhythmic bursting activity at theta frequencies is tightly coupled to hippocampal theta waves: glutamic acid decarboxylase (GAD)-positive neurons are distributed in almost equivalent proportions between $\mathrm{T}$ type (burst-firing at trough of hippocampus theta) and $\mathrm{P}$ type (peak of hippocampus theta) whereas the parvalbumin/GAD+ are largely T type. ${ }^{136,154,155,158}$ Furthermore, the hyperpolarisation-activated and cyclic nucleotide-gated non-selective cation channel $(\mathrm{HCN})$ of some MS GABAergic neurons has been suggested to play a pacemaker role for theta oscillations ${ }^{154,156}$ by disinhibiting the hippocampal pyramidal cells via rhythmic inputs to hippocampal GABAergic interneurons. ${ }^{127,159}$ Activity changes within parvalbumin and/ or HCN neurons precede changes in hippocampal interneurons and theta rhythm. ${ }^{158}$

\section{Behaviour}

An important component of hippocampal network dynamics and plasticity during learning ${ }^{160}$ is the modulation of CA1 interneuron activity by the septohippocampal GABAergic pathway during salient sensation and locomotion. Furthermore, Cav3.1 T-type $\mathrm{Ca}^{2+}$ channels are highly expressed in the septohippocampal GABAergic projection neurons ${ }^{161}$ and are critically involved in controlling object exploration through modulating hippocampal type 2 theta rhythm. ${ }^{162}$ Specifically, optogenetic activation of this pathway in mice selectively enhances novel object exploration and type 2 theta rhythm, whereas inhibition of the same pathway decreases both exploration and the rhythm. ${ }^{162}$

\section{MS cholinergic neurons \\ Connectivity}

Medial septal cholinergic terminals project to all regions of the hippocampus, ${ }^{163,164}$ especially the stratum oriens of the CA1 and CA3 subfields. ${ }^{165-167}$ These terminals synapse with pyramidal cell dendrites ${ }^{168}$ and cell bodies and dendrites of GABA-containing and somatostatin-containing interneurons ${ }^{147,166,169,170}$ and dentate granule cells. ${ }^{171}$ As the majority of axon terminals are diffusely organised ${ }^{172}$ and do not associate with distinct postsynaptic sites, ${ }^{165,166,168,173}$ cholinergic transmission in the hippocampus is likely primarily mediated by volume transmission. The cholinergic projections to the hippocampus may therefore tonically maintain an extracellular ambient level of acetylcholine, ${ }^{174}$ leading to long-lasting effects. ${ }^{173,175}$

Acetylcholine release within hippocampal circuits results in the activation of both metabotropic muscarinic (mAChRs) and ionotropic nicotinic (nAChRs) acetylcholine (ACh) receptors. Nicotinic receptors are expressed in dentate granule cells, pyramidal cells and interneurons both presynaptically and postsynaptically, ${ }^{176}$ on interneuron axons terminating on excitatory and inhibitory neurons ${ }^{177-181}$ and at inhibitory synapses contacting pyramidal neurons. ${ }^{182}$ Muscarinic receptors are expressed in soma and dendrites of pyramidal neurons and granule cells, with a small fraction expressed on axons and terminals. ${ }^{183}$ These receptors are also found in interneurons ${ }^{184,185}$ and in fibres surrounding pyramidal cells. The highest density of expression is found presynaptically in GABAergic terminals projecting onto the perisomatic region of pyramidal cells, ${ }^{186-189}$ and postsynaptically in dendrites and cell bodies of interneurons in the stratum oriens and alveus of CA1, ${ }^{190}$ or in glutamatergic terminals. ${ }^{187}$

\section{Electrophysiology}

As a consequence of their presynaptic and postsynaptic location, muscarinic receptors can have diverse impacts on hippocampal neuronal activity, influencing the net effect of ACh. Choline acetyltransferase (ChAT)-positive neurons have a long duration spike ${ }^{136}$ and fire at a lower frequency ${ }^{136,191}$ during the inactive $(3.4 \pm 0.3 \mathrm{~Hz})$ compared with active behavioural state $(4.7 \pm 0.3 \mathrm{~Hz}) .{ }^{115} \mathrm{ACh}$ has an excitatory effect on GABAergic and glutamatergic neurons within the MS. ${ }^{141,192,193}$ Cation flux through nAChRs mediates fast excitatory synaptic responses. ${ }^{179,181,182,194-199}$ Fast membrane depolarisation triggers activation of voltage-gated $\mathrm{Ca}^{2+}$ channels, second messenger systems involving CAMP $^{200,201}$ and release from intracellular stores. ${ }^{202,203}$ Moreover, nAChRs may modulate pre-existing oscillatory states ${ }^{204,205}$ by enhancing a slow calcium-dependent potassium conductance that reduces the firing of stratum oriens interneurons. ${ }^{206}$ In contrast to the fast response produced by activation of nAChRs, mAChR-mediated transmission is slow, owing to their dependence on G-protein-coupled signalling mechanisms. ${ }^{207}$ Moreover, M1/M3 mAChR activation sharpens interneurons' firing precision to theta frequency input, leading interneurons to amplify theta oscillations. ${ }^{208}$

ACh can suppress or enhance presynaptic neurotransmitter release in the hippocampus. ${ }^{178,179,182,188,189,209-215}$ ACh can facilitate and induce hippocampal long-term potentiation (LTP) or depression (LTD). ${ }^{128,199,216-225}$ The precise mechanism and direction of modulation may depend on ACh concentration, the timing of its release, exposure time, and the temporal sequence of $\mathrm{nAChR}$ and $\mathrm{mAChR}$ activation in relation to ongoing neuronal activity. ${ }^{199,226-228}$

Cholinergic MS neurons can be selectively activated by optogenetics. ${ }^{115}$ The evoked hippocampal response involves direct activation of ChAT projections together with indirect activation of non-ChAT septal neurons. Hippocampal neurons respond with an initial inhibition followed by rebound potentiation, inhibition and biphasic response, including potentiation and subsequent inhibition. Optogenetic septal ChAT stimulation exerts frequency-dependent and behaviour-dependent effect on hippocampal formation. The spiking of hippocampal neurons is significantly increased by $50 \mathrm{~Hz}$ but not $10 \mathrm{~Hz}$ septal stimulation and spiking increase is higher for inactive behavioural state than for active behavioural state.

Although cholinergic neurons are not pacemakers for hippocampal theta oscillations, they are involved in the generation and modulation of some of their attributes. ${ }^{59,62,67,74,148-150,229,230}$ However, the long post-hyperpolarisation period, small Ih and slow firing rates characteristic of MS cholinergic neurons limit their capacity to pace theta-related rhythmically bursting activity. ${ }^{126,128,135,136,231}$ Moreover, selective lesioning of MS cholinergic neurons reduces the number of rhythmically bursting neurons in the $\mathrm{MS}^{232}$ but does not eradicate hippocampal theta. ${ }^{151}$ Cholinergic MS neurons have been shown to display very slow, theta-unrelated firing in vivo, suggesting that these neurons might not act as pacemakers but rather generate theta activity via the tonic excitation of MS GABAergic and glutamatergic neurons ${ }^{136,141,192}$ and hippocampal interneurons and principal cells. ${ }^{166}$ Although in vivo coupling between phasic ACh release and theta oscillations has been shown, theta initiation was found not to require Ach. ${ }^{191}$ Cholinergic neurons firing was also seen to follow theta oscillations, making them pro-arousal and not pacemaker neurons for hippocampal theta oscillations. ${ }^{191}$

Cholinergic neurons also modulate the amplitude of theta oscillations. Microdialysis of ACh release ${ }^{152}$ and selective lesions of septohippocampal cholinergic neurons ${ }^{233}$ showed that cholinergic neurons selectively modulate the amplitude of theta oscillations, and not its frequency. ${ }^{136,234}$ Optogenetic activation of MS cholinergic neurons affects hippocampal oscillations in the 
theta range in a behaviour-dependent and frequency-dependent manner. Theta and gamma both significantly increase for inactive compared with active rodents ${ }^{115,234}$ and for low-frequency stimulation $(8-10 \mathrm{~Hz}){ }^{115}$ The overall tone of ACh is lower under urethane anaesthesia than in the awake animal ${ }^{235,236}$ and the faster theta seen during movement is largely non-cholinergically mediated, whereas the cholinergic input provides a background of sensory input-related drive to the hippocampus during movement. ${ }^{100}$ Another robust effect of optogenetic activation of MS cholinergic neurons in both anaesthetised and behaving mice is the suppression of slow oscillations in the supratheta frequency band. ${ }^{234}$

Cholinergic neurons have been found to play a role in hippocampal theta and synaptic plasticity. For instance, the local field synchronisation expressed a preference for a low-frequency stimulation protocol, whereas the hippocampal neuronal response showed significant increase after $50 \mathrm{~Hz}$ but not after $10 \mathrm{~Hz}$ optogenetic septal stimulation. ${ }^{115}$ While slow-spiking septal cholinergic neurons are linked to the amplitude of theta rhythm ${ }^{233}$ by tonically depolarising pyramidal cells and basket interneurons, ${ }^{237}$ the fast-spiking septal GABAergic cells are linked to the frequency of theta rhythm by periodically hyperpolarising hippocampal basket cells and rhythmically disinhibiting the pyramidal cells. ${ }^{159}$

\section{Behaviour}

Optogenetic cholinergic stimulation of the MS does not exert a consistent effect on locomotion velocity and motor behaviour. ${ }^{114,115,234}$ In fact, inhibition from different classes of interneurons create gamma oscillations within each theta cycle, and the modulated efficacy of excitatory inputs at different theta phases can selectively influence the timing of pyramidal cell firing. ${ }^{238}$ Therefore, promotion of co-ordinated firing and rhythmic activity by ACh release may provide an increase in the baseline excitability of neurons. This results in enhanced neural responses to glutamate and promotes neural interactions facilitating memory formation. Within this system, synaptic input that arrives during the positive phase of theta induces LTP while input that occurs during the negative phase induces LTD or depotentiation. ${ }^{239-243}$ In addition, cholinergic receptor activation enhances LTP induction during exploration ${ }^{218}$ and theta entrained hippocampal place cell activity. ${ }^{222}$ Therefore, high cholinergic tone during phases of exploration, in synergy with optimally timed theta, enhances plasticity.

\section{MS glutamatergic neurons}

Connectivity

Some glutamatergic neurons within the MS provide functional excitatory input to local cholinergic and GABAergic neurons. ${ }^{132,140,141,244}$ Others send direct projections to a restricted number of pyramidal cells and interneurons in the hippocampus. ${ }^{137,245}$

\section{Electrophysiology}

Medial septal glutamatergic neurons expressing type 2 vesicular glutamate transporters (VGluT2) are likely involved in hippocampal theta generation. ${ }^{132,135,140}$ They display a heterogeneous firing pattern, including fast, slow, burs, and clusterfiring $(8-14 \mathrm{~Hz}$, half of glutamatergic neurons) properties in slice. ${ }^{135,137}$ Glutamatergic neurons also have intrinsic firing properties that may play an important role in pacing the hippocampus in vivo: they can discharge in recurrent clusters of action potentials, interspersed with intrinsically generated subthreshold membrane potential oscillations. ${ }^{135}$

\section{Behaviour}

Before the onset of locomotion, the hippocampus undergoes a transition into an activity-state specialised for the processing of spatially related input. This brain-state transition is associated with increased firing rates of CA1 pyramidal neurons and the occurrence of theta oscillations, which both correlate with locomotion velocity. ${ }^{56,62,246-250}$

Fuhrman et al showed that the SHP mediated by glutamatergic (VGluT2+) neurons is activated before locomotion onset and controls the initiation and velocity of locomotion as well as the entrainment of theta oscillations. ${ }^{251}$ Septohippocampal projections onto alveus/oriens interneurons regulate inhibition of Schaffer collateral and perforant path input to CA1 pyramidal neurons in a locomotion-dependent manner. Accordingly, with faster locomotion, the increased activity of medial septal VGluT2 neurons is translated into increased axo-somatic depolarisation and higher firing rates of CA1 pyramidal neurons. Conversely, rhythmic activation of septal glutamatergic neurons can powerfully drive hippocampal theta oscillations through local septal interactions with GABAergic and cholinergic neurons ${ }^{251,252}$ rather than through direct glutamatergic projections to the hippocampus. ${ }^{252}$ Indeed, Robinson et al found that glutamatergic neurons provide prominent excitatory inputs to a majority of local GABAergic and a minority of septal cholinergic neurons. ${ }^{252}$

In contrast, activation of MS glutamatergic fibre terminals in hippocampal slices elicited weak postsynaptic responses in hippocampal neurons. Thus, MS VGluT2 neurons may couple neuronal firing rates and theta oscillations to movement velocity. Moreover, Fuhrman et al showed the in vivo role of MS VGluT2 neurons in the pre-motor control of locomotion. ${ }^{251}$ Firing of MS VGluT2 resulted in reliable initiation of locomotion, and also the firing rate and number of activated VGluT2 neurons directly correlated with the speed and the duration of locomotion. The pre-motor activity of MS VGluT2 neurons predicted the speed and delay to onset of the upcoming movement. In parallel, the pre-motor activation of MS VGluT2 neurons led to reliable entrainment of hippocampal theta oscillations before locomotion onset. Furthermore, Furhman et al raised the possibility that a small fraction of VGluT2-positive septohippocampal axons may directly excite the dendritic compartment of pyramidal neurons. ${ }^{251}$

Together, these findings strongly suggest an important role of the MS VGluT2 circuitry in the concerted initiation of locomotion and theta oscillations and in the active regulation of locomotion speed.

\section{Septohippocampal pathway summary}

Overall, MS burst-firing GABAergic neurons are important in generating, maintaining and pacing hippocampal theta activity by modulating GABAergic hippocampal interneurons and, indirectly, pyramidal cells. ${ }^{127,151,158,159,253}$ In turn, slow-firing cholinergic cells modulate theta amplitude. ${ }^{232,233}$ Septal glutamatergic neurons provide dense connections within the septum and comparatively sparse projections across the hippocampus: their rhythmic activation can powerfully drive hippocampal rhythms through local septal interactions rather than through direct projections to the hippocampus. ${ }^{252}$

Furthermore, spontaneous activity of MS neurons can be influenced by different inputs from the locus coeruleus, raphe 


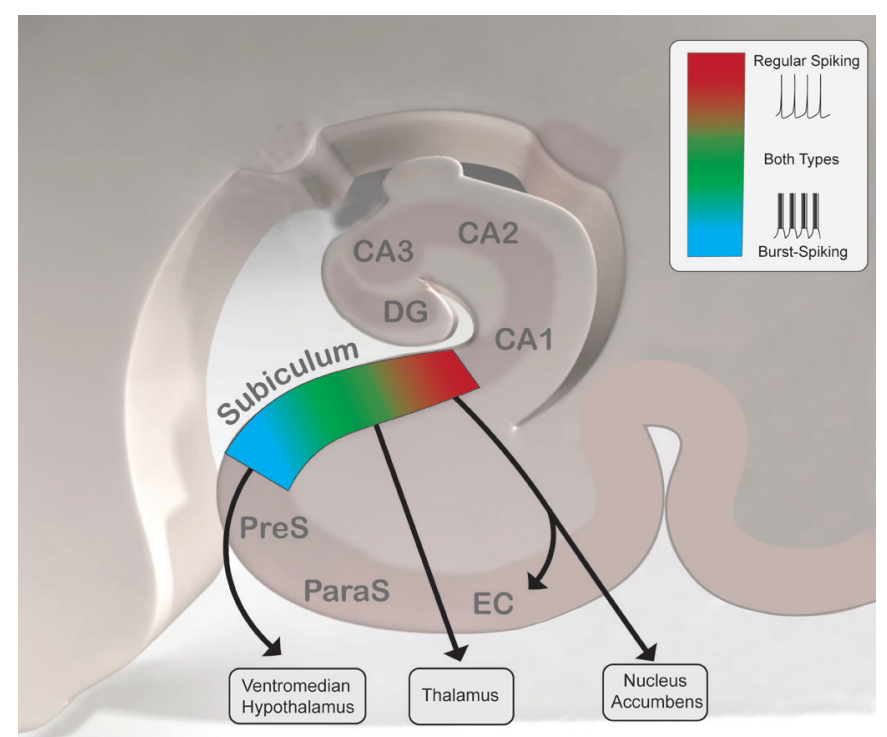

Figure 3 Topographical organisation and spatial projection of regular-spiking and burst-spiking neural subpopulations within the subiculum. Pyramidal neurons are divided into two groups based on their electrophysiological properties: regular-spiking and bursting neurons. Regular-spiking neurons fire with 60-160 ms interspike intervals, whereas bursting neurons fire at high frequency with decreasing successive spike amplitudes. EC, entorhinal cortex; PreS, presubiculum; ParaS, parasubiculum; DG, dentate gyrus.

nuclei and hypothalamus. ${ }^{254,255}$ Therefore, in addition to acting as one of several extrinsic rhythm generators that work in concert to amplify and regulate intrinsic theta generators within the hippocampus, the MS may relay and pace theta rhythm by integrating inputs from neighbouring brain regions. ${ }^{256}$ Taken together, a neurophysiologically-inspired septal DBS protocol should combine at minimum a low-frequency cholinergic-like and high-frequency GABAergic-like stimuli.

\section{SUBICULOTHALAMIC PATHWAY}

Subicular projections to the anterior thalamic nuclei (ATN) and the mammillary bodies (MB) connect distant nodes of the circuit of Papez and propagate the theta rhythm generated by the MS. To understand the role of these projections, anatomy, physiology and functions of these nodes will be explored.

\section{Subiculum}

The subiculum constitutes the major output structure of the hippocampal formation. ${ }^{257}$ As the final relay in a polysynaptic loop between the entorhinal cortex (EC) and the hippocampus, it integrates and distributes processed spatial and mnemonic information to cortical and subcortical brain regions. ${ }^{258}$ Pyramidal neurons, which form the chief output of the subiculum, are divided into two main groups based on their firing mode: regular-spiking and bursting neurons (figure 3). ${ }^{259-263}$ Regularspiking neurons fire a single action potential with $60-160 \mathrm{~ms}$ interspike intervals, whereas bursting neurons emit 2-5 action potentials at high frequency (2-5 ms interspike intervals) with decreasing successive spike amplitudes ${ }^{260,262,263}$ followed by a 20-30 ms refractory period with subsequent return to spiking. Bursting neurons are better suited to discriminate the content of high-frequency input, such as that occurring during gamma oscillations, than regular-spiking neurons. ${ }^{262}$ Interneurons are also found in the subiculum, as fast spiking units with an inter-spike interval of $7-10 \mathrm{~ms}$ and small spike width $(<0.2 \mathrm{~ms})$. There are more bursting than non-bursting neurons in the subiculum and both groups are distributed in an organised fashion along the proximal-distal axis, with more regular-spiking neurons close to CA1, and more bursting neurons close to the presubiculum. ${ }^{260,262}$ Moreover, there are distinct output targets in different portions of subiculum. ${ }^{257,258,264-268}$ The subiculum can be divided in four regions following the dorso-ventral and the proximo-distal axes, each of which serves as the origin of different parallel efferent projections with very few collateralisation. ${ }^{265,269-271}$ Bursting and regular spiking cells mainly target mainly respectively the presubiculum and the EC. ${ }^{272}$ Neurons projecting to the nucleus accumbens are located in the proximal subiculum and consist mostly of regular-spiking neurons $(\sim 80 \%)$ whereas neurons projecting to the ventromedial hypothalamus are located in the distal subiculum consisting mostly of bursting neurons $(\sim 80 \%)$, and neurons projecting to thalamus are located in the middle portion of subiculum with a bursting probability of $50 \% .^{273}$ Differences in the distribution and projection of regular-spiking and bursting neurons suggest that different types of information are conveyed from the subiculum to its various targets. Furthermore, the subiculum is capable of intrinsically generating two major memory relevant network rhythms: $\mathrm{SWR}^{274}$ and gamma oscillations. ${ }^{275}$ Gamma activity arises after tetanic stimulation of the subiculum or the hippocampal CA1 region. ${ }^{276,277}$ SWR might mediate memory consolidation and gamma oscillations the encoding of new information. A relatively small proportion of subicular recordings are phase-locked to theta. Nevertheless, similar to the hippocampus, subicular EEG is characterised by theta oscillations dominating exploratory behaviours, while SWR occur mainly during alert, still and quiet behaviours.

Several studies have investigated subicular functional connectivity and plasticity. ${ }^{278}$ In 2000, Gigg and colleagues showed that stimulation of CA1 produced excitation-inhibition sequences in bursting and non-bursting subicular principal cells and interneurons. ${ }^{278}$ The predominant subicular response to EC stimulation was weak inhibition, suggesting that EC bypasses the hippocampus, modulating the output of the subiculum and thus hippocampal-cortical interaction. Finally, a small depolarising response is observed when CA3 is stimulated and there is no response to dentate gyrus stimulation. ${ }^{263}$ Commins et al found in vivo paired pulse facilitation (interstimulus interval of $50 \mathrm{~ms}$ ) as well as LTP by high-frequency stimulation and TBS at the CA1subiculum synapse. ${ }^{279-281}$ One hertz low-frequency CA1 stimulation induced frequency-dependent LTD in bursting neurons and LTP in regular spiking subicular neurons, and this bidirectional plasticity relied on the co-activation of muscarinic ACh receptors. ${ }^{282}$ Finally, EC-subiculum synapses respond to low frequency-induced LTD $^{283}$ and high frequency-induced LTP. ${ }^{284}$

In parallel, several studies have reported that subicular neurons show spatially selective firing. ${ }^{80,285-287}$ Subicular neurons can be divided into three general classes: neurons coding head direction, neurons the firing rate of which reflects position but is modulated by head direction and neurons encoding place. ${ }^{288}$ The main output of CA1 is subiculum, but subicular place fields appear to be of lower resolution than those of CA1. ${ }^{287}$ Interestingly, the CA1 and subiculum have been found to operate in a complementary fashion to encode information in a spatial delayed-non-match-to-sample task. ${ }^{289}$ Subicular neural responses in this task were generally related to shorter delays $(15 \mathrm{~s}$ or less); conversely, CA1 neural activity was related to long-delay $(>15 \mathrm{~s})$ trial-specific information. Finally, the subiculum receives a direct projection from the perirhinal cortex, where neurons are responsive to the novelty or familiarity of objects encountered in 
the environment but subicular cell firing correlates best not with object novelty or familiarity, but with the concurrent location and speed of animals within the task environment. ${ }^{290}$

\section{Anterior thalamic nuclei}

As a node within the Papez circuit, the ATN gather two main types of neurons: local GABAergic and glutamatergic thalamocortical neurons. ${ }^{291,292}$ The ATN are composed of the anteroventral, anterodorsal and anteromedial thalamic nuclei. They are reciprocally connected with the presubicular, retrosplenial and cingulate cortices, and their major input arises in the MB. The ATN are distinguished by their subcortical sources of input, which are mainly derived from the hippocampal formation, either directly from the subicular complex $257,293,294$ or through a relay in MB. ${ }^{295,296}$ The para/postsubiculum distributes selectively to the anterodorsal thalamic nucleus, the presubiculum to the anteroventral thalamic nucleus and the proximal part of the subiculum almost exclusively to the anteromedial thalamic nucleus. ${ }^{257,267}$ The hippocampal projection to the MB, which comprises a major part of the descending columns of the fornix, predominantly originates from the dorsal subiculum and to some degree from the presubiculum and parasubiculum. ${ }^{257,294,297}$

The ATN carry electrophysiological and functional properties related to the intrinsic hippocampal rhythms (tables 3 and 4). Neurons firing rhythmically with theta, the so-called theta cells, and neurons firing selectively when a rat is oriented in a particular direction $(41 \mathrm{~Hz})$, the so-called head-direction cells, ${ }^{288,298}$ coexist in the ATN. Membrane properties of ATN neurons enable them to fire at frequencies between 5 and $11 \mathrm{~Hz},{ }^{299-301}$ so that some neurons in all divisions of ATN fire rhythmically with theta $(6-11 \mathrm{~Hz}),{ }^{302-304}$ with the highest percentage in the anteroventral thalamic nucleus $(35 \%-75 \%) .{ }^{301-303}$ In freely moving rats, the great majority of anteroventral thalamic nucleus cells are bursting (87.5\%) and $23.7 \%$ of those bursting thalamic units are highly entrained to limbic theta rhythm, which corresponds to periods of high locomotor activity. Their bursting is phaselocked to the trough of the local field oscillation. ${ }^{304}$

There is little overlap between theta rhythm and headdirection neurons. Instead, these cells are mainly present in the anterodorsal nucleus of the thalamus. ${ }^{288,305,306}$ Such a segregation is also observed in other nodes of the circuit of Papez such as posterior cingulate cortex, the subiculum, the hippocampus and the EC. ${ }^{288,307}$ Thus, the various subnuclei comprising these parallel, but segregated, theta and head-direction systems are themselves anatomically interconnected, with little crossover between systems. These systems may functionally interact at multiple levels of the circuit to process head-direction information used for spatial learning and navigation. ${ }^{308}$

\section{Mamillary bodies}

The lateral and medial MB are connected with different subregions in the same structures. Dense hippocampal projections from the rostral (septal) subiculum pass through the post-commissural fornix to terminate in the medial $\mathrm{MB}$ while parallel projections to the lateral $\mathrm{MB}$ arise from the presubiculum, parasubiculum and postsubiculum. ${ }^{309,310}$ Moreover, whereas the medial MB projects ipsilaterally to the anterior medial and anterior ventral thalamic nuclei, the lateral MB projects bilaterally to the anterior dorsal thalamic nucleus. Finally, the lateral MB have reciprocal connections with the dorsal tegmental nucleus of Gudden, and the medial MB has reciprocal connections with the ventral tegmental nucleus of Gudden. Both lateral and medial MB are 
Table 4 Stimulation of the post-commissural ventral fornix in rodents and human patients, along with main findings

\begin{tabular}{|c|c|c|}
\hline Study & Model & Main findings \\
\hline Hamani et $a l^{3}$ & 1 obese patient & Acute $130 \mathrm{~Hz}$ DBS induced old memories recall \\
\hline Laxton et al 2010 & 6 Patients with AD & $\begin{array}{l}\text { Clinical trial phase I: forniceal DBS was safe and drove neural activity in the memory circuit, including the entorhinal and } \\
\text { hippocampal areas, and activated the brain's default mode network }\end{array}$ \\
\hline Sankar et al 2015 & Patients with $A D$ & $\begin{array}{l}\text { In addition to modulating neural circuit activity, forniceal DBS influenced the natural course of brain atrophy in a } \\
\text { neurodegenerative disease }\end{array}$ \\
\hline Hescham et al 2015a & Rats & $\begin{array}{l}1 \text { hour of } 100 \mathrm{~Hz} \text { DBS increased c-Fos in CA1 and CA3 and led to ACh increase in hippocampus peaking } 20 \text { min after } \\
\text { stimulus onset, and no change of glutamate }\end{array}$ \\
\hline Zhang et al 2015 & Rats with hippocampal AP 1-42 & 24-hour-long DBS facilitated hippocampus-dependent spatial memory 4 weeks later \\
\hline Hescham et al 2016 & Rats & Acute $100 \mathrm{~Hz}$ DBS improved performance in Morris Water Maze test \\
\hline Hescham et al 2013 & Rats, IP scopolamine & $\begin{array}{l}\text { Forniceal DBS reversed the memory impairing effects of scopolamine. DBS efficacy was not sensitive to the frequency of } \\
\text { stimulation, but rather to current levels }\end{array}$ \\
\hline
\end{tabular}

also innervated by the supramammillary nuclei, the tuberomammillary nucleus and the septal region. ${ }^{31}$

Inputs to $\mathrm{MB}$ from both the hippocampal formation and the prefrontal cortex are excitatory, but the projections from the tegmental nuclei are inhibitory. ${ }^{310} \mathrm{MB}$ efferents to both anterior thalamic and tegmental nuclei are excitatory. ${ }^{311,312}$ Neurochemically, the efferents from MB to the ATN use glutamate, aspartate and enkephalin. ${ }^{312}$

Head-direction neurons are found in the lateral MB, but not the medial MB of the rat. Head-direction signals in the lateral $\mathrm{MB}$ precede the signal in the anterior thalamus indicating that the lateral mammillary signal helps to drive the thalamic signal. ${ }^{305,313}$ Moreover, medial MB neurons fire rhythmically in phase with hippocampal theta, ${ }^{314}$ whereas few such cells exist in the lateral MB. Septal inactivation eliminates theta activity in the MB but not in the adjacent supramammillary nucleus, ${ }^{48}$ suggesting that $\mathrm{MB}$ is part of a descending system driven from the septum/hippocampus, whereas the supramammillary nucleus is a part of an ascending system generating theta. ${ }^{315}$ Thus, the $\mathrm{MB}$ are a key relay of hippocampal theta rhythm to the ATN and distal circuits.

The MB likely contribute to memory via processes at least in part independent from their hippocampal inputs, such as afferents from the limbic mesencephalon. ${ }^{31}$ For instance, the pathway responsible for maintaining head direction in rats originates in the dorsal tegmental nucleus of Gudden and projects to the lateral $\mathrm{MB}$, terminating in the anterodorsal thalamic nuclei. Conversely, the regulation of theta rhythm and the optimisation of synaptic plasticity originates in the ventral tegmental nucleus of Gudden, projects to the medial $\mathrm{MB}$ and terminates in the anteroventral thalamic nuclei. ${ }^{307,313}$

\section{Subiculothalamic projections}

Anterior thalamic functions rely on direct hippocampal inputs through the direct pathway, as well as indirect information via the indirect pathway. ${ }^{316}$ The subicular cells projecting to the $\mathrm{MB}$ also project to the EC, while the direct subiculothalamic cells do not. ${ }^{271}$ Since these distinct cell populations may not mediate the same functions, knowing the electrophysiological properties of their synapse with ATN neurons, especially their plasticity and latent periods, is crucial in order to modulate them appropriately with DBS.
Electrical stimulation of the dorsal fornix (figure 2) evokes distinct electrophysiological responses due to stimulation of direct and indirect subiculothalamic cells. In particular, a triphasic response is seen in ATN neurons consisting of a small negative wave followed by a small positive wave and then a long negative wave, with latent periods of 1.5 to 4 ms. ${ }^{317}$ After a first shock applied to the $\mathrm{MB}$, a period of decreased responsiveness follows the orthodromic activation of AT cells, with a peak at $40 \mathrm{~ms}$ and lasting 70-80 ms. MB stimuli delivered at low frequencies $\leq 1 \mathrm{~Hz}$ or $>2 \mathrm{~Hz}$ evoke respectively a $220 \mathrm{~ms}$ long triphasic or monophasic inhibitory postsynaptic potentials in most ATN neurons of preclinical models. ${ }^{291}$ The hippocampo-mammillary axon terminals were stimulated by Laxton et al at $3 \mathrm{~Hz}$ in six patients with $\mathrm{AD}$ : the peak of the first evoked response had a $38-52 \mathrm{~ms}$ latency and was localised to the hippocampal and parahippocampal gyri, likely corresponding to antidromic activation. At longer latencies (102-256 ms), significant activation of the posterior cingulate gyrus and precuneus area of the parietal lobe was seen suggesting previous activation of the ATN to low frequencies.

Prolonged high-frequency stimulation applied to either the dorsal fornix or the mammillothalamic tract (MTT) did not result in long-lasting thalamic theta activity in rats (table 5). Moreover, 15 min-1 Hz low-frequency stimulation of the dorsal fornix induced augmentation of thalamic low-theta and high-theta over delta ratios for about $120 \mathrm{~min}$ in parallel with depressing thalamic synaptic responses whereas the same protocol applied to MTT failed to evoke significant oscillatory changes. ${ }^{301,304}$ Synaptic depression has been proposed as a dynamic gain control mechanism in cortical information processing ${ }^{318}$ and hippocampal theta may modify thalamic responsiveness to stimuli coming from the tegmental area via the MB. Differences in basal synaptic transmission, short-term and long-term synaptic plasticity were found between the hippocampo-thalamic and mammillothalamic tracts. A brain-derived neurotrophic factor-dependent augmentation of synaptic transmission was observed only at mammillothalamic synapses. Paired-pulse stimulation, however, induced facilitation in both pathways. The amplitude of the thalamic activity was readily potentiated after high-frequency stimulation of the mammillothalamic tract but not of the dorsal fornix. Lowfrequency stimulation of the mammillothalamic tract induced potentiation. ${ }^{301,304}$ Seemingly, the two major inputs to the ATN have opposing or complementary actions. 
Table 5 Stimulation of the dorsal fornix or the mammillothalamic tract in rodent models

\begin{tabular}{|c|c|c|c|c|}
\hline Outcome & Species & $\begin{array}{l}\text { Stimulation } \\
\text { frequency }(\mathrm{Hz})\end{array}$ & Dorsal fornix & Mammillothalamic tract \\
\hline \multirow[t]{2}{*}{ Thalamic theta oscillations } & \multirow[t]{2}{*}{ Rat } & 1 & $\begin{array}{l}\text { Increase of theta power (Tsanov et } \\
\text { al 2011c) }\end{array}$ & No increase of theta power (Tsanov et al 2011c) \\
\hline & & 100 & $\begin{array}{l}\text { No increase of theta power } \\
\text { (Tsanov et al 2011c) }\end{array}$ & No increase of theta power (Tsanov et al 2011c) \\
\hline \multirow[t]{2}{*}{ Thalamic synaptic plasticity } & \multirow[t]{2}{*}{ Rat } & 1 & $\begin{array}{l}\text { LTD of FP slope and amplitude (Tsanov } \\
\text { et al 2011d) }\end{array}$ & LTP of FP slope and amplitude (Tsanov et al 2011d) \\
\hline & & 100 & $\begin{array}{l}\text { LTP of the FP slope, no effect on FP } \\
\text { amplitude (Tsanov et al 2011d) }\end{array}$ & LTP of FP slope and amplitude (Tsanov et al 2011d) \\
\hline \multirow[t]{2}{*}{ Biochemistry } & \multirow{2}{*}{$\begin{array}{l}\text { Rat scopolamine IP } \\
(0.1 \mathrm{mg} / \mathrm{kg})\end{array}$} & 10 & - & \multirow{2}{*}{$\begin{array}{l}\text { c-Fos increase in infralimbic and prelimbic cortices } \\
\text { (Hescham et al 2015b) }\end{array}$} \\
\hline & & 100 & - & \\
\hline \multirow[t]{2}{*}{ Memory } & \multirow{2}{*}{$\begin{array}{l}\text { Rat scopolamine IP } \\
(0.1 \mathrm{mg} / \mathrm{kg})\end{array}$} & 10 & - & No effect on object location task (Hescham et al 2015b) \\
\hline & & 100 & - & No effect on object location task (Hescham et al 2015b) \\
\hline
\end{tabular}

FP, field potential; IP, intraperitoneal; LTD, long-term depression; LTP, long-term potentiation.

Following clinical trials of human fornix stimulation, Hescham showed in 2016 that 1 -hour stimulation at $100 \mathrm{~Hz}$ of the hippocampo-mammillary axon terminals induced a selective activation of cells in the CA1 and CA3 subfields of the rodent dorsal hippocampus. ${ }^{319}$ In addition, they observed a substantial increase in the levels of extracellular hippocampal ACh, which peaked $20 \mathrm{~min}$ after stimulus onset, whereas hippocampal glutamate levels did not change compared with baseline. In a rat model of scopolamine-induced dementia, acute bilateral DBS of the hippocampo-mammillary axon terminals reversed the memory impairing effects of scopolamine in the object location task. ${ }^{320}$ Both $10 \mathrm{~Hz}$ and $100 \mathrm{~Hz}$ stimulations were found to be efficient, but a higher current density threshold was needed at $10 \mathrm{~Hz}$.

\section{Human forniceal subiculo-mammillary stimulation}

Several trials have documented the clinical effects of chronic forniceal subiculo-mammillary axon terminals for DBS (table 4). In a patient with morbid obesity, bilateral DBS to the hypothalamus, which is closely associated with the ventral post-commissural fornix, elicited recall of autobiographical DBS was initiated: patients with mild-to-moderate AD were implanted with electrodes $2 \mathrm{~mm}$ anterior to the columns of the ventral post-commissural fornix. Patients received highfrequency DBS for 12 months, and PET studies a year later revealed increases in cortical glucose metabolism that were correlated with improved cognitive measures in two orthogonal networks: a frontal-temporal-parietal-striatal-thalamic network and a frontal-temporal-parietal-occipital-hippocampal network. $^{321}$ The finding of increased glucose metabolism is a striking contrast to the longitudinal metabolic decline generally seen in patients with $\mathrm{AD} .{ }^{322,323}$ Moreover, clinical evaluation of the AD Assessment Scale cognitive subscale (ADAS-Cog) and the Mini Mental State Examination (MMSE) suggested possible slowing in the rate of progressive cognitive decline in certain patients with $\mathrm{AD} .^{321,324}$ In the aforementioned cortical regions, higher baseline metabolism prior to DBS and increased metabolism after 1 year of DBS were correlated with better outcomes in global cognition, memory and quality of life. A single case report showed evidence of stabilisation of MMSE and ADAS-Cog scores at 1-year follow-up and subjective improvement. ${ }^{325}$ Although a subsequent crossover randomised phase II clinical trial did not yield cognitive benefits in all patients with $\mathrm{AD}$, those over the age of 65 showed a slower decline. ${ }^{326}$ A multicentre phase III memories. ${ }^{3}$ Subsequently, an open-label phase I trial of fornix

trial is now underway to assess which $\mathrm{AD}$ patient subgroup will benefit most from forniceal DBS. ${ }^{5}$

\section{Subiculothalamic pathway summary}

Overall, a characteristic feature of the anterior thalamic neurons is their ability to fire rhythmically in the theta range. ${ }^{327}$ These $5-12 \mathrm{~Hz}$ oscillations in the anterior ventral nucleus of the thalamus receive descending inputs from the subiculum and ascending inputs from the medial MB via the forniceal subiculothalamic pathway. ${ }^{307}$ Theta rhythm is thought to play a critical role in the mnemonic functions of the limbic system ${ }^{64,315,328}$ and

Table 6 Presence of theta and/or gamma oscillations within the various nodes of the Papez circuit interconnected by the fornix, and effects of electrical stimulation of these nodes

\begin{tabular}{|c|c|c|}
\hline Target & Theta oscillations & Gamma oscillations \\
\hline $\begin{array}{l}\text { Medial septum } \\
\text { - - Cholinergic }\end{array}$ & $\begin{array}{l}\text { Projections to hippocampus } \\
\text { enhance hippocampal } \\
\text { theta rhythm }\end{array}$ & - \\
\hline $\begin{array}{l}\text { Medial septum } \\
\text { - - GABAergic }\end{array}$ & $\begin{array}{l}\text { Projections to hippocampus } \\
\text { enhance hippocampal type } \\
2 \text { theta rhythm }\end{array}$ & - \\
\hline $\begin{array}{l}\text { Medial septum } \\
\text { - - Glutamatergic }\end{array}$ & $\begin{array}{l}\text { Projections to } \\
\text { hippocampus do not } \\
\text { influence hippocampal } \\
\text { theta }\end{array}$ & - \\
\hline $\begin{array}{l}\text { Hippocampus } \\
\text { (CA1, CA3, DG) }\end{array}$ & Intrinsic theta oscillations & $\begin{array}{l}\text { Intrinsic gamma } \\
\text { oscillations }\end{array}$ \\
\hline Entorhinal cortex & Intrinsic theta oscillations & $\begin{array}{l}\text { Gamma oscillations; } \\
\text { drives hippocampal } \\
\text { gamma oscillations at the } \\
\text { trough of hippocampal } \\
\text { theta at the level of the } \\
\text { hippocampal fissure } \\
\text { (Senova et al 2018) }\end{array}$ \\
\hline Subiculum & $\begin{array}{l}\text { Occasional theta } \\
\text { oscillations; } \\
\text { projections enhance } \\
\text { thalamic theta power }\end{array}$ & $\begin{array}{l}\text { Intrinsic gamma } \\
\text { oscillations }\end{array}$ \\
\hline $\begin{array}{l}\text { Anterior thalamus } \\
(A D, A V, A M)\end{array}$ & Intrinsic theta oscillations & - \\
\hline Mammillary bodies & $\begin{array}{l}\text { Theta oscillations; } \\
\text { projections to the anterior } \\
\text { thalamus do not influence } \\
\text { thalamic theta }\end{array}$ & - \\
\hline
\end{tabular}


oscillatory patterns in the theta range may enable synaptic plasticity. ${ }^{109}$ Furthermore, inactivation of the MS and thus of the forniceal septohippocampal pathway abolishes theta discharge in both the hippocampus and $\mathrm{MB},{ }^{48,329}$ two of the major regions providing inputs to anterior thalamus. Hence, the ATN appear to be part of a descending system driven from the MS via the forniceal septohippocampal pathway, and theta oscillations in the anterior thalamus might complement hippocampal-diencephalic memory processing after propagation through the forniceal subiculothalamic pathway. ${ }^{308}$

\section{Overall summary and future directions}

Understanding the complex interconnections within the circuit of Papez mediated by the fornix sheds light on memory function in healthy and disease states. This framework is also relevant in the context of the design of future clinical forniceal DBS strategies. The forniceal septohippocampal axis generates brain oscillations that are central to memory processes, such as theta and gamma oscillations, as well as theta-gamma cross-frequency coupling (table 6). The forniceal subiculothalamic pathway relays these rhythms across the nodes of the circuit of Papez, mediating diverse functional aspects of memory. The topography of projections and interplay of intrinsic rhythms give rise to synaptic plasticity and memory consolidation. Given the complex neurophysiology and connectivity of subnodes within the circuit of Papez, future neuromodulation devices should strive to deliver individualised therapy in various nodes of the circuit of Papez in response to real-time electrophysiological data. ${ }^{330}$ Biotechnological innovations in the field of neuromodulation are needed to optimise sensing and delivery algorithms, as well as power management strategies in future DBS devices. Prospective randomised and double-blinded human trials are underway to evaluate the true potential of DBS to rescue memory deficits in patients with neurodegenerative, vascular or traumatic lesions of the circuit of Papez. ${ }^{5}$ Please see online supplementary file 1 for references 61 to 308 .

Contributors SS and AF are joint first authors and contributed equally to the manuscript. SS conceived the manuscript and wrote the first draft. AF created figures, wrote the anatomy and pathology chapters and revised the manuscript. EG contributed the imaging and clinical trials chapter. AL oversaw revisions and approved the final manuscript.

Funding This review was made possible by the R.R. Tasker Chair in Functional Neurosurgery, University Health Network (AML) and the University of Manitoba Clinician Investigator Program (AF)

Competing interests AML is a consultant to Medtronic, St Jude, Boston Scientific, Functional Neuromodulation and Insightec.

Patient consent for publication Not required.

Provenance and peer review Not commissioned; externally peer reviewed.

Open access This is an open access article distributed in accordance with the Creative Commons Attribution Non Commercial (CC BY-NC 4.0) license, which permits others to distribute, remix, adapt, build upon this work non-commercially, and license their derivative works on different terms, provided the original work is properly cited, appropriate credit is given, any changes made indicated, and the use is non-commercial. See: http://creativecommons.org/licenses/by-nc/4.0/.

\section{ORCID iDs}

Anton Fomenko http://orcid.org/0000-0003-4131-6784

Andres M Lozano http://orcid.org/0000-0001-8257-3694

\section{REFERENCES}

1 Douet V, Chang L. Fornix as an imaging marker for episodic memory deficits in healthy aging and in various neurological disorders. Front Aging Neurosci 2014;6:343.

2 Rowland NC, Sammartino F, Tomaszczyk JC, et al. Deep brain stimulation of the fornix: engaging therapeutic circuits and networks in Alzheimer disease. Neurosurgery 2016;63 Suppl 1:1-5.
3 Hamani C, McAndrews MP, Cohn M, et al. Memory enhancement induced by hypothalamic/fornix deep brain stimulation. Ann Neurol 2008;63:119-23.

4 Lozano AM, Fosdick L, Chakravarty MM, et al. A phase II study of fornix deep brain stimulation in mild Alzheimer's disease. J Alzheimers Dis 2016:54:777-87.

5 ADvance II Study: DBS-f in Patients With Mild Alzheimer's Disease. ClinicalTrials.gov 2019.

6 Lang J. Topographic anatomy of preformed intracranial spaces. In: Bauer BL, Hellwig D, eds. Minimally invasive neurosurgery I. Vienna: Springer Vienna, 1992: 1-10.

7 Ozdogmus O, Cavdar S, Ersoy Y, et al. A preliminary study, using electron and lightmicroscopic methods, of axon numbers in the fornix in autopsies of patients with temporal lobe epilepsy. Anat Sci Int 2009;84:2-6.

8 Tsivilis D, Vann SD, Denby C, et al. A disproportionate role for the fornix and mammillary bodies in recall versus recognition memory. Nat Neurosci 2008;11:834-42.

9 Bozoki AC, Korolev IO, Davis NC, et al. Disruption of limbic white matter pathways in mild cognitive impairment and Alzheimer's disease: a DTI/FDG-PET study. Hum Brain Mapp 2012:33:1792-802.

10 Szabo K, Hennerici M. The hippocampus in clinical neuroscience. Basel: Karger, 2014: 1-161.

11 Paxinos G, Watson C. The rat brain in stereotaxic coordinates. 7th edn, 2018. https:// www.elsevier.com/books/the-rat-brain-in-stereotaxic-coordinates/paxinos/978-0-12391949-6

12 Strange BA, Witter MP, Lein ES, et al. Functional organization of the hippocampal longitudinal axis. Nat Rev Neurosci 2014;15:655-69.

13 Kerever A, Kamagata K, Yokosawa S, et al. See-through brains and diffusion tensor MRI clarified fiber connections: a preliminary microstructural study in a mouse with callosal agenesis. Magn Reson Med Sci 2015;14:159-62.

14 Demeter S, Rosene DL, van Hoesen GW. Interhemispheric pathways of the hippocampal formation, presubiculum, and entorhinal and posterior parahippocampal cortices in the rhesus monkey: the structure and organization of the hippocampal commissures. J Comp Neurol 1985;233:30-47.

15 Andy OJ, Stephan H. The septum in the human brain. J Comp Neurol 1968;133:383-409.

16 Demeter S, Rosene DL, Hoesen GWV. The extent and organization of the primate hippocampal commissure: 2:30 PM. Neurology, 1983. Available: https://insights. ovid.com/neurology/neur/1983/04/002/extent-organization-primate-hippocampalcommissure/128/00006114 [Accessed 1 Apr 2018].

17 Gloor P, Salanova V, Olivier A, et al. The human dorsal hippocampal commissure. An anatomically identifiable and functional pathway. Brain 1993;116:1249-73.

18 Wyss JM, Swanson LW, Cowan WM. The organization of the fimbria, dorsal fornix and ventral hippocampal commissure in the rat. Anat Embryol 1980;158:303-16.

19 Rosene DL, Hoesen GWV. The hippocampal formation of the primate brain. Boston, MA: Cerebral Cortex. Springer, 1987: 345-456.

20 Garcia-Bengochea F, Friedman WA. Persistent memory loss following section of the anterior fornix in humans. A historical review. Surg Neurol 1987;27:361-4.

21 Gaffan EA, Gaffan D, Hodges JR. Amnesia following damage to the left fornix and to other sites: a comparative study. Brain 1991;114:1297-313.

22 Squire L, Zola-Morgan S. The medial temporal lobe memory system. Science 1991;253:1380-6.

23 Aggleton JP, McMackin D, Carpenter K. Differential cognitive effects of colloid cysts in the third ventricle that spare or compromise the fornix. Brain 2000;123:800-15.

24 Adamovich BL, Gualberto G, Roberts T, et al. Teaching Neurolmages: amnesia due to fornix infarction. Neurology 2009;73:e86.

25 Baweja R, Mensinkai A, Reddy K, et al. Fornix infarction after clipping of anterior communicating artery aneurysm. Can. J. Neurol. Sci. 2015;42:205-7.

26 Cameron A, Archibald Y. Verbal memory deficit after left fornix removal: a case report. Int J Neurosci 1981;201.

27 Hodges JR, Carpenter K. Anterograde amnesia with fornix damage following removal of IIIrd ventricle colloid cyst. J Neurol Neurosurg Psychiatry 1991;54:633-8.

28 McMackin D, Cockburn J, Anslow P, et al. Correlation of fornix damage with memory impairment in six cases of colloid cyst removal. Acta Neurochir 1995;135:12-18.

29 Saunders RC, Aggleton JP. Origin and topography of fibers contributing to the fornix in macaque monkeys. Hippocampus 2007;17:396-411.

30 Tucker DM, Roeltgen DP, Tully R, et al. Memory dysfunction following unilateral transection of the fornix: a hippocampal disconnection syndrome. Cortex 1988;24:465-72

31 Dillingham CM, Frizzati A, Nelson AJD, et al. How do mammillary body inputs contribute to anterior thalamic function? Neurosci Biobehav Rev 2015;54:108-19.

32 Bloom GS. Amyloid- $\beta$ and tau: the trigger and bullet in Alzheimer disease pathogenesis. JAMA Neurol 2014;71:505-8.

33 La Joie R, Visani AV, Baker SL, et al. Prospective longitudinal atrophy in Alzheimer's disease correlates with the intensity and topography of baseline tau-PET. Sci Trans/ Med 2020;12:eaau5732.

34 Stratmann K, Heinsen H, Korf H-W, et al. Precortical phase of Alzheimer's disease (AD)-related tau cytoskeletal pathology. Brain Pathology 2016;26:371-86.

35 Rüb U, Stratmann K, Heinsen H, et al. The brainstem tau cytoskeletal pathology of Alzheimer's disease: a brief historical overview and description of its anatomical 
distribution pattern, evolutional features, pathogenetic and clinical relevance. Curr Alzheimer Res 2016;13:1178-97.

36 McKinnon C, Gros P, Lee DJ, et al. Deep brain stimulation: potential for neuroprotection. Ann Clin Trans/ Neurol 2019;6:174-85.

37 Akwa Y, Gondard E, Mann A, et al. Synaptic activity protects against AD and FTD-like pathology via autophagic-lysosomal degradation. Mol Psychiatry 2018;23:1530-40.

38 Jeong J. Eeg dynamics in patients with Alzheimer's disease. Clin Neurophysiol 2004:115:1490-505

39 Kowalski JW, Gawel M, Pfeffer A, et al. The diagnostic value of EEG in Alzheimer disease: correlation with the severity of mental impairment. J Clin Neurophysiol 2001:18:570-5.

40 Besthorn C, Förstl H, Geiger-Kabisch C, et al. EEG coherence in Alzheimer disease. Electroencephalogr Clin Neurophysiol 1994;90:242-5.

41 Fletcher E, Raman M, Huebner $\mathrm{P}$, et al. Loss of fornix white matter volume as a predictor of cognitive impairment in cognitively normal elderly individuals. JAMA Neurol 2013;70:1389-95

42 Oishi K, Lyketsos CG. Editorial: Alzheimer's disease and the fornix. Front Aging Neurosci 2016;8:149

43 Callen DJA, Black SE, Gao F, et al. Beyond the hippocampus. Neurology 2001;57:1669.

44 Copenhaver BR, Rabin LA, Saykin AJ, et al. The fornix and mammillary bodies in older adults with Alzheimer's disease, mild cognitive impairment, and cognitive complaints: a volumetric MRI study. Psychiatry Res 2006;147:93-103.

45 Oishi K, Mielke MM, Albert M, et al. The fornix sign: a potential sign for Alzheimer's disease based on diffusion tensor imaging. J Neuroimaging 2012;22:365-74.

46 Mielke MM, Kozauer NA, Chan KCG, et al. Regionally-specific diffusion tensor imaging in mild cognitive impairment and Alzheimer's disease. Neuroimage 2009;46:47-55.

47 Winson J. Loss of hippocampal theta rhythm results in spatial memory deficit in the rat. Science 1978;201:160-3.
48 Oddie SD, Stefanek W, Kirk IJ, et al. Intraseptal procaine abolishes hypothalamic stimulation-induced wheel-running and hippocampal theta field activity in rats. $J$ Neurosci 1996;16:1948-56

49 Leutgeb S, Mizumori SJ. Excitotoxic septal lesions result in spatial memory deficits and altered flexibility of hippocampal single-unit representations. J Neurosci 1999:19:6661-72.

50 Scoville WB, Milner B. Loss of recent memory after bilateral hippocampal lesions. $J$ Neurol Neurosurg Psychiatry 1957:20:11-21.

51 Morris RGM, Garrud P, Rawlins JNP, et al. Place navigation impaired in rats with hippocampal lesions. Nature 1982;297:681-3.

52 O'Keefe J, O'Keefe J. Place units in the hippocampus of the freely moving rat. Exp Neurol 1976;51:78-109.

53 O'Keefe J, Recce ML. Phase relationship between hippocampal place units and the EEG theta rhythm. Hippocampus 1993;3:317-30.

54 Wood ER, Dudchenko PA, Eichenbaum H. The global record of memory in hippocampal neuronal activity. Nature 1999;397:613-6.

55 Fenton AA, Lytton WW, Barry JM, et al. Attention-like modulation of hippocampus place cell discharge. J Neurosci 2010;30:4613-25.

56 Buzsáki G, Lai-Wo S. L, Vanderwolf CH. Cellular bases of hippocampal EEG in the behaving rat. Brain Res Rev 1983;6:139-71.

57 Bland BH. The physiology and pharmacology of hippocampal formation theta rhythms. Prog Neurobiol 1986;26:1-54.

58 Vertes RP, Kocsis B. Brainstem-diencephalo-septohippocampal systems controlling the theta rhythm of the hippocampus. Neuroscience 1997:81:893-926.

59 Kramis R, Vanderwolf $\mathrm{CH}$, Bland BH. Two types of hippocampal rhythmical slow activity in both the rabbit and the rat: relations to behavior and effects of atropine, diethyl ether, urethane, and pentobarbital. Exp Neurol 1975;49:58-85.

60 Kahana MJ, Seelig D, Madsen JR. Theta returns. Curr Opin Neurobiol 2001;11:739-44 